\title{
Contribuição ao conhecimento das Gnetáceas da Amazônia (Gimnospermas)
}

\author{
Paulo B. Cavalcante ( $\left.{ }^{(}\right)$
}

\begin{abstract}
Resumo
A familia Gnetaceae, com um único gênero Gnetum, encontra-se nas zonas tropicais em três centros de distribuição: Ásia, com cerca de 25 espécies, África Ocidental com duas espécies e Amazônia com seis espécies. Com mais as familias Ephedraceae e Welwitschiaceae, esse pequeno grupo de gimnospermas é altamente diferenciado das outras gimnospermas por muitas caracteristicas. A colocação dessas familias nesse taxon é devido unicamente à presença do caráter óvulo nu. As seis espécies amazônicas estăo diferentemente distribuidas. G. urens ocorre somente no estuário, não indo além da boca do rio Jari. G. schwackeanum e G. paniculatum ocorrem somente no Estado do Amazonas. G. nodiflorum é o mais freqüente e distribui-se por toda a região, para o lado esquerdo do rio Amazonas. G. leyboldii, ao contrário, sendo menos freqüente está disperso mais para o lado sul da Hiléia. G. venosum concentra.se na zona Bragantina e boca do Guamá, subindo o rio Amazonas até Manaus. As duas primeiras espécies acima sāo próprias de capoeiras e campinas de terra firme năo alagáveis. enquanto que as demais estão estreitamente relacionadas a ambientes aquáticos, beira de rios, igapós, etc. Todas as espécies são conhecidas pelo nome popular de "ituá" e fornecem uma amêndoa comestivel. O caule, rico em fibras, é utilizado em forma de corda para vários fins.
\end{abstract}

\section{INTRODUÇÃo}

Até recentemente admitia-se a ordem Gnetales com uma só familia - Gnetaceae e esta composta dos gêneros Ephedra, Welwitschia e Gnetum, embora fosse evidente a quase total ausência de afinidades entre estes très gêneros. Tal fato interessou vários botânicos a empreenderem estudos morfológicos e embriológicos, cujos resultados levaram à conclusão de que as Gnetales constituem um agrupamento isolado e os três gêneros são apenas remo. tamente relacionados uns aos outros (Lawrence 1951: 368). Segundo Pearson (apud Croizat, 1952: 268), as afinidades das Gnetales com outrăs gimnospermas e com as angiospermas são tão obscuras que sua discussão não seria prática. Entre vários autores que evidenciaram a heterogeneidade dos três gêneros, Eames (1952) sugeriu a criaçăo de três ordens distintas, cada uma com uma família monogenérica. Essas familias passaram a constituir uma Divisão autônoma, figurando nos tratados modernos de Botânica Sistemática, conforme o seguinte esquema :

$$
\begin{aligned}
& \text { Divisão Gnetophyta } \\
& \text { Ordem 1. Ephedrales } \\
& \text { Familia: Ephedraceae } \\
& \text { Gênero: Ephedra } \\
& \text { Ordem 2. Gnetales } \\
& \text { Familia: Gnetaceae } \\
& \text { Gênero: Gnetum } \\
& \text { Ordem 3. Welwitschiales } \\
& \text { Familia: Welwitschiaceae } \\
& \text { Gênero: Welwitschia }
\end{aligned}
$$

Filogeneticamente, as Gnetófitas já foram consideradas como um elo de ligação entre gimnospermas e angiospermas o que, aparentemente, era aceitável. Entretanto, essa hipótese foi rejeitada por falta de suporte paleontológico; segundo Lawrence (l.c.), ainda näo foi comprovada a existência de gnetófitos no Cretáceo, pois, como é sabido, nesse período as angiospermas já dominavam.

\section{DISTRIBUIÇÃO GEOGRÁFICA}

O gênero Ephedra tem larga distribuição pela Ásia, Europa e Américas; Welwitschia restringe-se ao sudoeste da África; Gnetum tem três centros de distribuição, limitados às áreas tropicais úmidas. O primeiro e maior deles, com cerca de 25 espécies, encontra-se na Ásia; o segundo, com 6 espécies está na América do Sul; finalmente, o terceiro centro de distribuição, com 2 espécies, localiza-se no oeste da Africa. As espécies americanas mos-

$\left({ }^{*}\right) \longrightarrow$ INPA - Museu Paraense Emilio Goeldi, Belém. 
tram mais afinidades com as espécies africanas, o que é explicado por Markgraf (1930) como uma decorrência da teoria da deriva continental.

$\mathrm{Na}$ região amazônica, as seis espécies estão diferentemente distribuídas, conforme indicam as coleções feitas até o presente.

G. paniculatum Spruce ex Benth. (map. II), restringe-se ao quadrante noroeste da Amazônia compreendido entre o rio Negro, a partir de Manaus, rio Branco, ne T. F. Roraima e o Solimões. Sua maior concentração está no alto rio Negro e seu afluente Uaupés.

G. urens (Aubl.) BI. (map. I). Pouco freqüente, limitado ao estuário, de Calçoene (T. F. Amapá) a Bragança (Pará), penetrando no rio Amazonas somente até a boca do rio Jari.

G. leyboldii Tul. (map. II). Distribui-se pelos tributários da margem direita do Amazonas e embocadura dos afluentes esquerdos, com ocorrência mais acentuada no Estado do Pará. G. nodiflorum Brongn. (map. II). É a espécie mais freqüente, praticamente distribuída por toda a região, exceto no quadrante sudeste. G. schwackeanum Taub. (map. I). Disperso, mas não freqüente, por todo o Estado do Amazonas, ultrapassando ligeiramente seu limite com o Pará, no alto Tapajós.

G. venosum Spruce ex Benth. Pará e Amazonas, (map. I), com notável freqüência na zona Bragantina e boca do rio Guamá; sobe o rio Amazonas e parte inferior de alguns tributários, não indo além de Manaus.

\section{HABJTAT}

As gnetáceas habitam as áreas de baixa altitude cobertas de florestas, porém ocorrem também em savanas, campinas ou capoeiras. Quase como uma regra não são encontrados no interior na mata mas, sim, nos limites desta

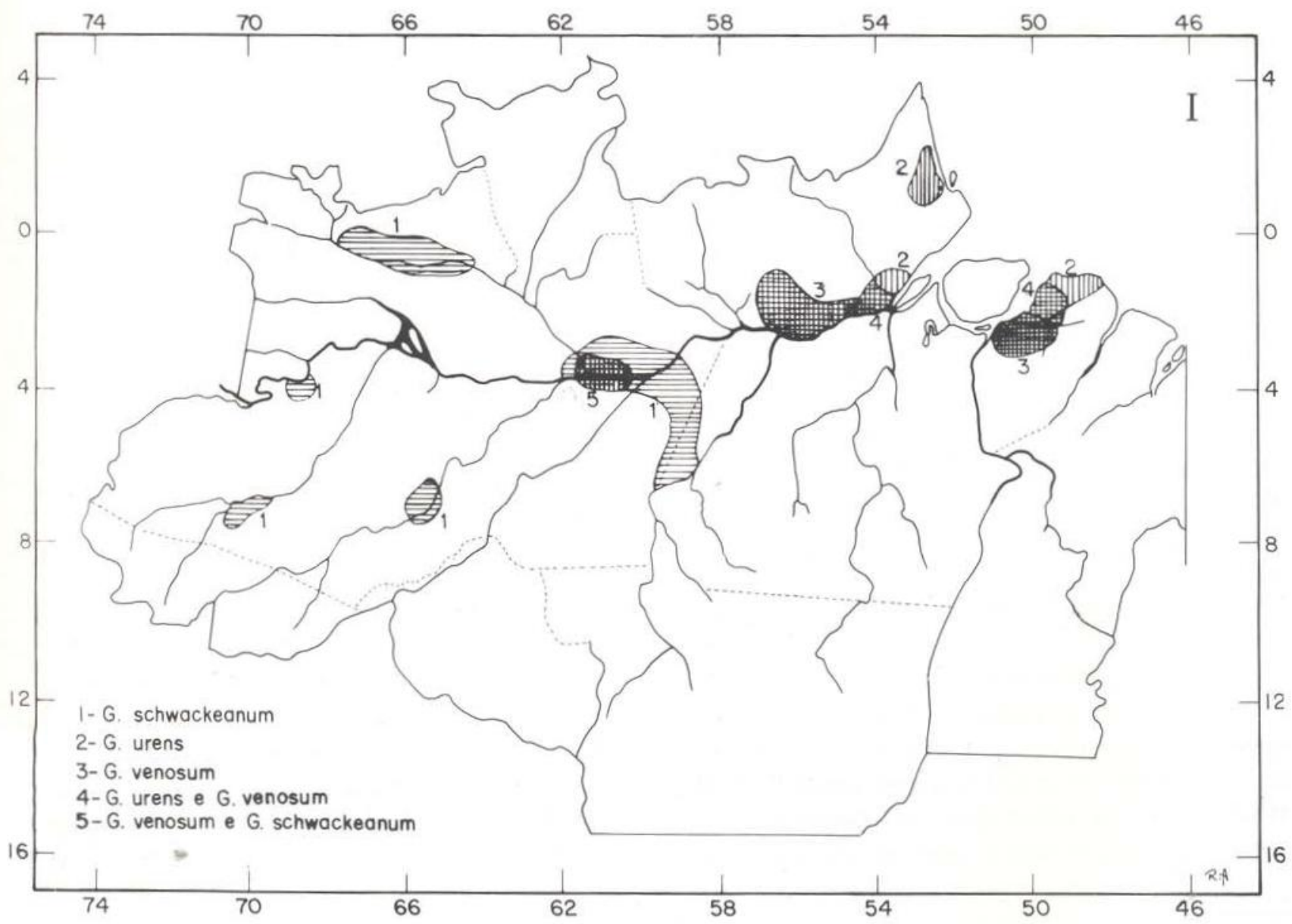




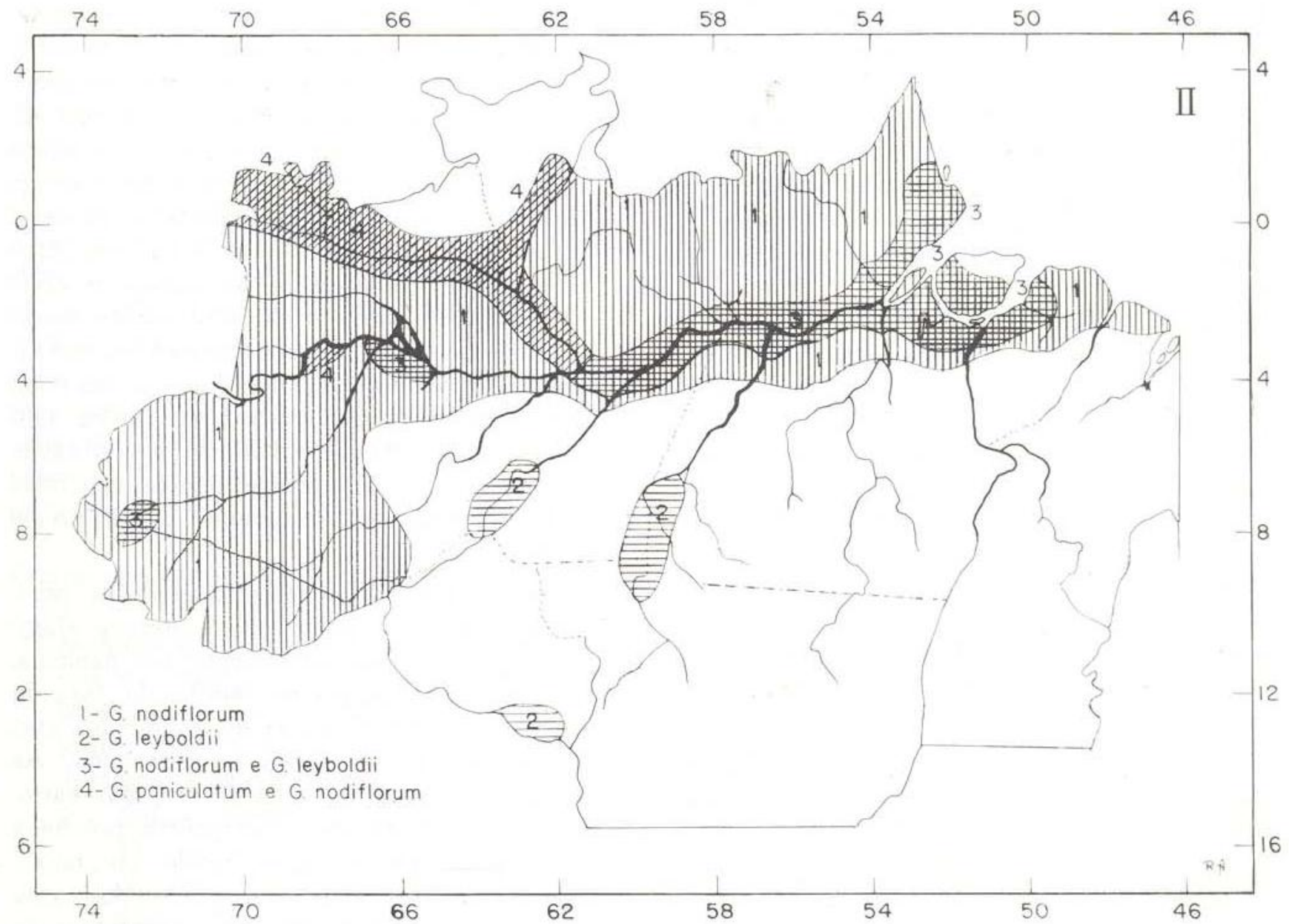

com os rios, furos, canais e igarapés. G. venosum e G. leyboldii têm o seu habitat quase invariável nas margens pantanosas ou periodicamєnte alagáveis, onde a parte inferior do caule fica submersa. G. schwackeanum e G. urens são da terra firme não alagável, de capoeiras, campinas e campos, arenosos ou não. G. nodiflorum pode ocorrer em beira de rios ou na mata de terra firme e em campinaranas. G. paniculatum está relacionado aos rios de água preta como é o caso do Negro e alguns de seus afluentes.

As espécies ripícolas têm a sua dispersão garantida pelas águas, que transportam os frutos a longas distâncias, muitas vezes recolhidos pelas populações ribeirinhas, que os aproveitam como alimento.

\section{IMPORTÂNCIA ECONÔMICA}

Os frutos (') das espécies asiáticas $G$. gnemon e G. ula são comestíveis depois de assados ou cozidos e por isso estas espécies são comumente cultivadas em algumas regiões daquele continente. As amêndoas são reduzidas a uma pasta e, em seguida, moldadas em bolos e biscoitos, levadas ao sol para secar e depois fritas em óleo.

As espécies amazônicas também fornecem frutos comestíveis, muito apreciados pelas populações interioranas. Os frutos são assados em brasas e, depois de removida a casca, as amêrıcioas são logo comidas ou então podem ser transformadas em "farinha de ituá". As vezes essa farinha é produzida em tal quanti-

(1) - Tratando-se de Gimnospermas logicamente que é semente, porém, essa estrutura nas Gnetáceas é muito diferente nas outras Gimnospermas e tem toda apa rência de um fruto verdadeiro e, porisso, para simplificar, denominaremos "fruto". 
dade que se torna necessário armazená-la em paneiros como é tradicionalmente feito com a farinha de mandioca $\left({ }^{2}\right)$. O sabor da amêndoa lembra o da castanha européia (Castanea vesca) .

Nos rios e furos do estuário, é freqüente o uso das sementes principalmente das espécies $G$. leyboldii e $G$. venosum como isca para a pesca do "bacu" (Lithodorus dorsalis), peixe de regular tamanho.

O caule é rico em fibras resistentes e duráveis, aproveitado para vários fins, no estado natural, isto é, como "cipó", ou pode ser transformado em cordas rústicas, bastando batê-lo com um cepo ou martelo e em seguida torcê-lo. Essas cordas, grosseiras mas resistentes, geralmente são utilizadas no transporte da borracha em "lingadas", nos altos rios; a corda é passada pelo furo de várias "peles" ou "bolas" de borracha, formando a "lingada", que fica sobre a água e atrelada a uma embarcação, sendo, assim, transportadas a longas distâncias.

King (apud Medina, 1959: 45), que estudou especialmente as fibras produzidas nas Filipinas, assevera que as cordas fabricadas com fibras de Gnetum são mais resistentes à tração e ruptura do que todas as cordas produzidas nesse país à base das fibras vegetais de espécies indígenas.

\section{NOMES POPULARES}

As seis espécies são conhecidas em toda a região pela designação popular de "ituá" ou "itoá". G. schwackeanum e G. urens, cujos frutos são pequenos, menores que os das outras espécies, são conhecidos por "ituá-i". Nalgumas das outras espécies, os frutos, ao atingirem plena maturação, tornam-se de um roxo carregado, parecendo preto, dai o nome de "ituá preto". Para os índios do alto rio Negro, G. paniculatum é "curucuda" e G. leyboldii "corocoro".

\section{Sistemática}

Gnetum Linn. Mant. 1:18, n. ${ }^{\circ} 1278,1767$; L. R. Tulasne, in: Mart., Fl. Bras. 4(1): 399, 1863; Fr. Markgraf, Bul. Jard. Bot. Buitenz., ser. 3, 10(4): 408, 1930.
O gênero Gnetum é representado na Amazônia por seis espécies, cujo hábito se assemelha bastante às angiospermas dicotiledô. neas. Todas as seis espécies são cipós trepadores de porte variável. O caule pode atingir até $20 \mathrm{~cm}$ de diâmetro na base, tendo uma casca muito resistente; às vezes, quando cortado, exuda um látex resinoso amarelado. O caule principal e suas ramificações imediatas, inteiramente destituidas de folhas, sobem as árvores altas e dai descem as ramificações de ordens menores nas quais encontram-se folhas, flores e frutos. Principalmente nos caules mais finos, nota-se a presença de articulações, isto é, nós e entrenós bem distintos e são esses nós uma das características que tornam mais fácil o imediato reconhecimento do gênero no campo.

Folhas opostas simples, pecioladas, peninervadas, sem estipulas, quase sempre elipticas. Inflorescência geralmente em panícula, pouco ou abundantemente ramificada, laxa ou compacta, dióica, formada de segmentos curtos ou longos - os cones ou estróbilos. As flores agrupam-se em volta do eixo dos estróbilos, formando nódulos superpostos, próximos ou afastados um do outro, tendo, por baixo, duas brácteas opostas e conatas em forma de concha ou de prato, referida na literatura de lingua inglesa como "collar". O número e forma das brácteas colares e o comprimento dos entrenós separando-as, são caracteres de importáncia especifica (Maheshwari \& Vasil. 1962: 32). Nos estróbilos masculinos, encontram-se algumas flores femininas estéreis, dispostas em círculo em volta do eixo, e numerosos triccmas moniliformes entre ambos os tipos cle flores. A flor masculina isolada mede cerca de $0.5-1 \mathrm{~mm}$ e é extremamente simples consistindo de um envoltório - o perianto, no interior do qual há um único estame com dois microsporângios. A antese dá-se por uma fenda apical do perianto, projetando-se para fora apenas os microsporângios, cuja deiscência para libertação dos micrósporos é feita por uma fenda lateral-transversal. Flor feminina fértil (ou óvulo), de $2-5 \mathrm{~mm}$ de altura, geralmente de 2-6 em cada bráctea, chegando ao pleno desenvolvimento apenas 1 ou 2; de fora

(2) - Comunicação pessoal de J. M. Pires. 
para dentro apresentam as seguintes camadas: a) envoltório externo $\left({ }^{3}\right)$ algo espesso e carnoso; b) envoltório intermediário, delgado; c) envoltório interno, fino, prolongado superiormente em tubo longo, estreito, chamado tubo micropilar. No interior do envoltório mais interno, encontra-se um único óvulo, ortrótopo. Semente (para alguns autores, pseudofruto ou simplesmente fruto) elipsóide ou oblonga, variancio de tamanho, de $2,5-7 \mathrm{~cm}$ de comprimento e até $3 \mathrm{~cm}$ de diâmetro. Casca (envoltório) externa, lisa ou rugosa, amarela, vermelha ou roxa, as vezes contendo fibras esclerenquimáticas em forma de pequenos espinhos urentes, como em $G$. venosum e $G$. urens. O envoltório médio tem consistência coriácea e o interno papirácea.

\section{Chave PARA SEPaRAÇão DAS ESPÉCIES}

1. Nódulos das inflorescências distanciados uns dos outros até cerca de $1,8 \mathrm{~cm}$; brácteas dos nódulos em forma de concha ou prato, sem estreitamento para a base (estamp. 1, 2 e 3).

2. Folhas coriáceas, de $10-20 \mathrm{~cm}$ por $8-10 \mathrm{~cm}$; brácteas em forma de prato, de $3,5-5 \mathrm{~mm}$ de diâmetro; frutos de $4-5 \mathrm{~cm}$ por $2,5 \mathrm{~cm}$, com as extremidades arredondadas. Em toda a Amazônia, em matas, savanas ou campinas .... ................ G. nodiflorum

2a. Folhas cartáceas ou subcoriáceas, de $6-12 \mathrm{~cm}$ por $3-6 \mathrm{~cm}$ tornando-se pretas quando secas; brácteas em forma de concha; frutos $7-8 \mathrm{~cm}$, com as extremidades afiladas, às vezes a distal recurvada. Pará e Amazonas, em locais alagados .............. G. venosum

2b. Folhas subcoriáceas, $4-10 \mathrm{~cm}$ por $2-4 \mathrm{~cm}$, levemente enegrecidas quando secas; bráctea em forma de prato; fruto $4-5 \mathrm{~cm}$ por $1,5-2 \mathrm{~cm}$. Amazonas, terra firme .......... G. schwackeanum

1b. Nódulos das inflorescências bem aproximados, brácteas com a base gradativamente estreitadas (estamp. 4, 5 e 6).

3. Folhas coriáceas de $10-18 \mathrm{~cm}$ por $5-9 \mathrm{~cm}$, às vezes parcialmente enegre- cidas quando secas; brácteas masculinas em forma de prato, fruto cerca de $6 \mathrm{~cm}$ por $3 \mathrm{~cm}$. Amazonas, principalmente em rios de água preta.

\section{G. paniculatum}

3a. Folhas subcoriáceas ou cartáceas de $12 \mathrm{~cm}$ por $5 \mathrm{~cm}$; frutos mais ou menos elipsóides de $3-4 \mathrm{~cm}$ por $1,5 \mathrm{~cm}$. Pará, em descampados ou capoeiras de terra firme G. urens

3b. Folhas rígido-coriáceas, grandes, de $15-20 \mathrm{~cm}$ por $6-12 \mathrm{~cm}$; frutos oblongos, de $4-5 \mathrm{~cm}$ por $2 \mathrm{~cm}$. Em toda a regiāo, em locais alagados .... G. leyboldii

G. nodiflorum Brongn., Duperrey, Voy. sur la coquille, 1.12, 1829. Sin.: G. amazonicum Tul. Ann. Sc. Nat. ser. 4, 10:116, 1858; G. cruzianum Gleas., Bull. Torrey Bot. Cl. 52:196, 1925; G. oblongifolium Huber, Bol. Mus. Par. 3:403, 1902; G. paraense Huber, I.c. (Est. 1).

Cipó lenhoso, grosso, subindo a copa de árvores altas da beira da mata, ramos cilíndricos, articulado-nodosos. Folha: pecíolo até $1 \mathrm{~cm}$ de comprimento, cananiculado; lâmina coriácea, ovalada, elíptica ou elíptico-oblonga, variando de $10-20 \mathrm{~cm}$ de comprimento e $6-10 \mathrm{~cm}$ de largura, base arredondada, subcordada, aguda ou obtusa, às vezes assimétrica, ápice agudo ou acuminado; nervura principal impressa na face superior e saliente na inferior; nervuras laterais 4-5 pares, curvadas para o ápice, bem visíveis na face inferior e pouco distintas na superior. Inflorescência masculina em panícula bastante laxa, até $20 \mathrm{~cm}$ de comprimento; estróbilos alongados, de comprimento muito variável, nódulos floríferos distanciados uns dos outros até $1,8 \mathrm{~cm}$; brácteas colares em forma de prato, de $3,5-5 \mathrm{~mm}$ de diâmetro (as maiores do grupo); flor masculina obcônica cerca de $0,7 \mathrm{~mm}$ de altura, flor feminina elipsốide, $3-4 \mathrm{~mm}$ de altura. Fruto elipsóide, vermelho ou avermelhado, de $4-5 \mathrm{~cm}$ por $2,5 \mathrm{~cm}$.

As folhas desta espécie são muito parecidas com as de G. leyboldii, de maneira que exemplares estéreis dificilmente poderão ser separados. Localidade Tipica:, Caiena.

(3) - Markgraf considera o invólucro externo da flor masculina e da feminina como perianto; os dois invólucros, médio e interno da flor feminina, como integumentos. 


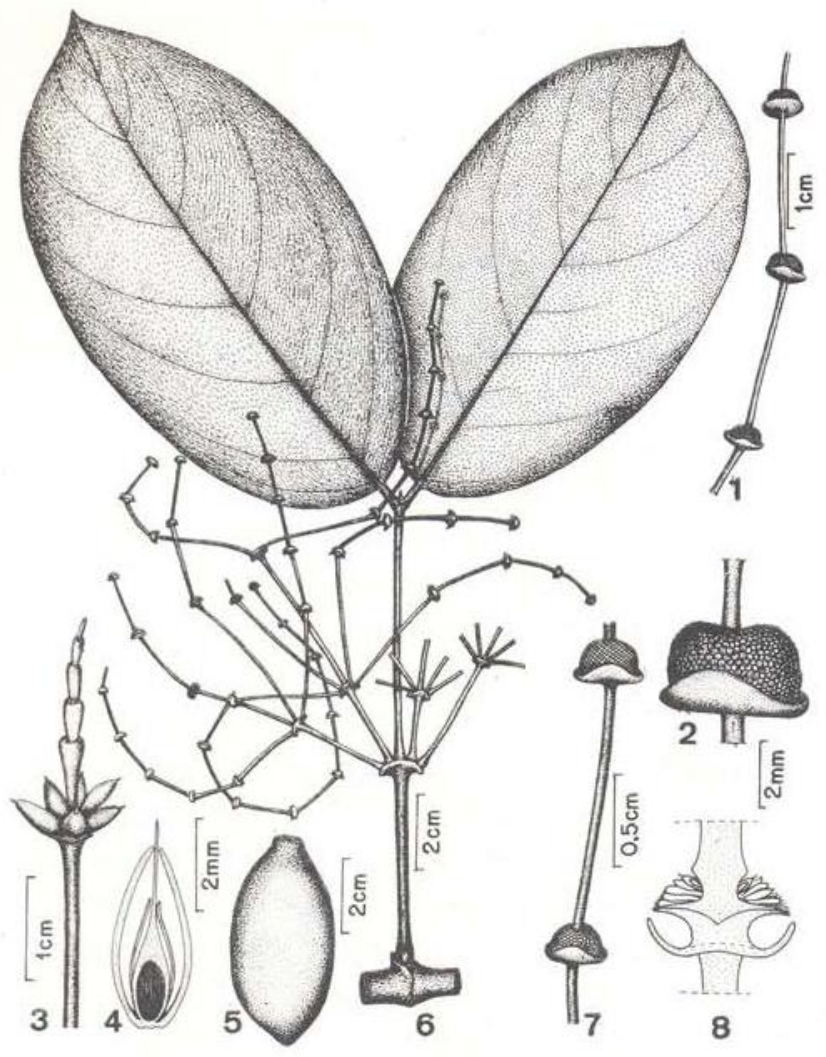

Est. $1-$ Gnetum nodiflorum : 1 e 7) detalhe da inflorescência masculina; 2) nódulo floral; 3) verticilo de flor feminina; 4) corte longitudinal de flor feminina; 5) fruto; 6) ramos com inflorescência masculina; 8) corte longitudinal de um nódulo floral masculino, mostrando flor fem. estéril.

\section{COLEÇÕES EXAMINADAS}

PARÁ. Belém, Instituto Agronômico do Norte (atualmente EMBRAPA-Pará), beira do rio Guamá, várzea, fruto, 20-XII-1950, G. A. Black 50-10924 (IAN); - ibidem, igarapé Murutucu, fr. jovem 19-XII-1950, J. M. Pires 2679 (IAN); - ibidem, beira do rio Guamá, "ituá", fr. maduro, 13-XII-1949, T. N. Guedes 228a (IAN). - Sta. Izabel, Estr. de Ferro de Bragança, fr. mad. 15-II-1947, A. Ducke 2067 (MG, IAN); - ibidem, estéril, 26-1-1948, N. T. Silva 109 (IAN); - ibidem, fr. mad. 10-V-1948, J. M. Pires 1190 (IAN). - Colares, Vigia, sítio Horizonte, fr. 29-IX-1954, G. A. Black 54-16935 (IAN). Moju, rio Cairari, fr. mad. 25-II-1957, R. L. Fróes 33131 (IAN). - Rio Moju, Fábrica, fr. 1-VI-1954, G. A. Black 54-16284 (IAN). - Tomé-Açu, rio Pequeno, fr. 24-XII-1948, J. M. Pires 1447 (IAN). - Breves, Antonio Lemos, igarapé Pixuna, estéril, 17-VII-1948, G. A. Black 48-2930 (IAN); - ibidem, fl. feminina 18-VII-1948, G. A. Black 48-2974 (IAN); - ibidem, igarapé Arapijó, fr. mad. 5--XI-1958, T. N. Guedes 661 (IAN); - ibidem, rio Aramá, fr. II-1900, J. Huber, MG 1863; - ibidem, furo Macujubim, estéril 30-VIII-1901, M. Guedes, MG 2214,
- Portel, itha do Breu, rio Pacajá, fr. imat. 21 XI-1965. G. T. Prance \& Al, 1436 (MG, INPA). - Almeirim, rio Caracuru, fr. mad. 4-V-1963, E. Oliveira 2529 (IAN); ibidem, rio Jari, Monte Dourado, entre Pilão e Repartimento, fr. 26-X-1968, N. T. Silva 1319 (IAN); - ibidem, estéril 20_III-1968, E. Oliveira 4205 (IAN). - Marabá, rio Vermelho, fl. masc 23-IV-1951, R. L. Fróes 26978 (IAN): - ibidem, serra dos Carajás, fl. fem. 28-VI-1976, B. G, S Ribeiro 1379 (IAN) . - Santarém, Cachoeira do rio Aruã, Arapiuns, fl. masc. 29-V-1952, J. M. Pires \& N. T. Silva 4212 (IAN); - ibidem, beira do rio Una, fr. jov. 10-VIII-1955, R. L. Fróes 32028 (IAN); ibidem, rio Curuátinga, beira, fr., 11-111-1965, R. L. Fróes, 31608 (IAN); - ibidem, fr., 11-III-1955, R. L. Fróes 31640 (IAN); - ibidem, fr., 11-III-1955, R. L. Fróes 31643 (IAN); - ibidem, Alter do Chão, fl. fem., 22-VI-1910, A. Ducke, MG 10824. - Óbidos, região do Ariramba, campo do Mutum, fl. masc. 28-V-1957, W. A. Egler 379 e G. A. Black 57-19672 (MG, IAN).; - ibidem,, fl. masc. 28-V-1957, W. Egler 330 e G. A. Black 57-19672 (MG, IAN). - Oriximiná, rio Mapuera. fr. jov., 5-XII-1907. A. Ducke, MG 9044 - Faro, Serra do Dedal, beira de Lago, fr, jov. 3IX-1907, A. Ducke, MG 8581. - Faro, rio Jamundá, várzea, fr. jovem, 12-XI-1950, Black et Ledoux 50-10745 (IAN)

T. F. AMAPÁ. Estrada para Amapá, km 134, Água Azul, fl. masc., 24-VII-1962, Pires \& Cavalcante (MG, IAN, NY, Amapá-Guyana 52260). - Rio Araguari, Porto Platon, $0^{\circ} 44^{\prime} \mathrm{N}-51^{\circ} 22^{\prime} \mathrm{W}, \mathrm{fl}$. masc. 15-VIII-1961, Pires, Rodrigues \& Irvine (MG, IAN, NY, Amapá-Guayana 50347); ibidem, entre as cachoeiras Travessão e Sta. Maria, $1^{\circ} \mathrm{g}^{\prime} \mathrm{N}-51^{\circ} 52^{\prime} \mathrm{W}, \mathrm{fl}$, masc., 20-VIII-1961, Pires, Rodrigues \& Irvine (MG, IAN, NY, Amapá-Guayana 50383); - ibidem, campos gerais de terra firme alta, fl. fem.. 22-VII-1951, R, L. Fróes \& G. A. Biack 27569 (IAN). Cunani, beira da mata, "ituá", fr., 13-X-1895, J. Huber, MG 1031.

GOIÁS. Rio Araguaia, igarapé Piranha, fl., 7-V-1961, E. Oliveira 1682 (IAN)

AMAZONAS. Manaus, rio Tarumã, mata sombria, acatingada, fl. Fem., 10-VIII-1949, R. L. Fróes 24973 (IAN). - Rio Cuieiras, abaixo da boca do rio Branquìnho, savana, "ituá", fl. masc., 25-IX-1971, G. T. Prance \& al 14817 (INPA); - ibidem, campina de areia branca, fr.. 28-IV-1975, G T. Prance \& J. Ramos 23394 (INPA). Estrada Manaus-Itacoatiara, Reserva CEPLAC, mata fr. imat., 24-IV-1974, G. T. Prance 20985 (INPA). - Estrada Manaus-Caracarai, $\mathrm{km}$ 45, Reserva Biológica do INPA, fr mad. 11/14-IV-1972, R. E. Schultes \& W. Rodrigues 26163A (INPA); - ibidem, fr. mad. amarelo, 24-II-1972, M. Honda \& P. Mello, INPA 35214; - ibidem, "ituá", fr. imat., 8-II-1972, M. F. Silva \& D. Coelho 52 (INPA). - Estrada Manaus-Porto Velho, entre os rios Castanho e Tupana, mata de terra firme, fr. imat., 17-VII-1972, M. F. Silva \& al 831 (INPA). - Lago Badajós, igapó, fl. jov., 24-VIII-1950, R. L. Fróes 26353 (IAN); - ibidem, fl. fem., 24-VIII-1950, R. L. Fróes 26360 (IAN). - Maués, praia alagável do rio, fr. mad... 30-XI-1946, J. M. Pires 147 (IAN). - Tefé, margem inundável de lago, fr. imat., 28-Il-1972, Byron \& al. 591 
(INPA); - ibidem, igarapé Sapiá, mata de terra firme, fl. masc., 16-VI-1950, R. L. Fróes 26282 (IAN). - Rio Urubu, S. Francisco, fr. imat., 3-X-1949, R. L. Fróes 25464 (IAN): - ibidem, entre as cachoeiras Lindoia e Iracema, margem inundada, fr. jov., 3-VI-1968, G. T. Prance \& al. 4939 (INPA): - ibidem, margem do rio, $\mathrm{fr}$. imat., 22-IX-1949, R. L. Fróes 25341 (IAN) - Rio Negro, São Gabrie| da Cachoeira, serra radioativa, fr. 13-III-1975, J. M. Pires \& L. R. Marinho 15791 (IAN). Rio Uaupés, Tupanaruca, "curucuda", fl, fem. 7-XI-1947. J. M. Pires 886 (IAN). - Rio Içana, entre Posto do Içana e Tunui, fr. mad., 14-V-1948, G. A. Black 48-2816 (IAN). - Rio Aracá, sub-afluente do Rio Negro, campinarana, fr. imat.. 24-X-1952, Fróes \& Addison 29047 (IAN): - ibidem, cachoeira, beira do rio, fr. jov., 29-X-1952, Fróes \& Addison 29179 (IAN). - Rio Purus, rio Curuquetê, São Paulo, ilha rochosa, fl. fem.. 20-VII-1971, G T Prance \& al. 14485 (INPA, MG); ibidem, entre cachoeira S. Paulo e República, mata de várzea, fr. jov.., 22-VII-1971, G. T. Prance \& al. 14507 (INPA, MG); - Rio Solimōes, rio Biá, afluente do Jutai, margem inundada, fr. imat., 5-IX-1975, L. Coelho \& al. 338 (INPA). - São Paulo de Olivença, Camatian, restinga baixa, fr. mad., 30-I-1949; R. L. Fróes 24030 (IAN). - Tabatinga, fronteira Brasil-Colômbia, submata, fr. $\operatorname{mad}$, , 2-XI-1945, J. M. Pires \& G. A. Black 1066 (IAN). - Rio Javari, Posto Militar Palmeiras, $72^{\circ} 49^{\prime} \mathrm{W}$. $5^{0} 8^{\prime} \mathrm{S}$, mata de terra firme, fr. mad., 2-VIII-1973, G. T. Prance \& al. 17072 (INPA, MG); - ibidem, fl. masc., 1-VIII-1973, G. T. Prance \& al. 17000 (INPA).

T. F. RORAIMA. Rio Anauá, base do Projeto RADAM:' próximo da maloca dos indios Auai, campo cerrado, $\mathrm{fl}$. masc., 6-XI-1973, B. S. Pena 339 (IAN).

ACRE. Cruzeiro do Sul, entre República e serra da Moa, mata, fr. mad., 19-IV-1971, G. T. Prance \& al. 12096 (INPA, MG).

MATO GROSSO. Aripuanã, Dardanelos, cipó, fr. imat.. 29-IX-1975, P. Lisboa \& al. 472 (INPA).

MARANHĀO. S. Luiz, rio Anil, estéril, 10-V-1949, R. L. Fróes 24220 (IAN).

G. venosum Spruce ex Benth, in : Hook Journ. of Bot. and Kew Gard. Misc. 8:358, 1856; Markgraf, Bull. Jard. Bot. Buiten., ser. 3, $10(4)$ : 451, 1930, (Est. 2) .

Cipó robusto. Folha: peciolo $0,6-10 \mathrm{~mm}$ de comprimento; lâmina elíptica ou obovadooblonga, assimétrica, enegrecida quando seca, subcoriácea ou cartácea, $6-13 \mathrm{~cm}$ de comprimento (raro até 15 ), por $3,5-6 \mathrm{~cm}$ de largura, ápice agudo ou subacuminado, base obtusa ou arreciondada; nervuras laterais bastante delicadas, eerca de 6-8 em cada lado da nervura central, às vezes em número diferente nos dois lados. Inflorescência masculina axilar, multiramificada, moderadamente laxa, com os entre-

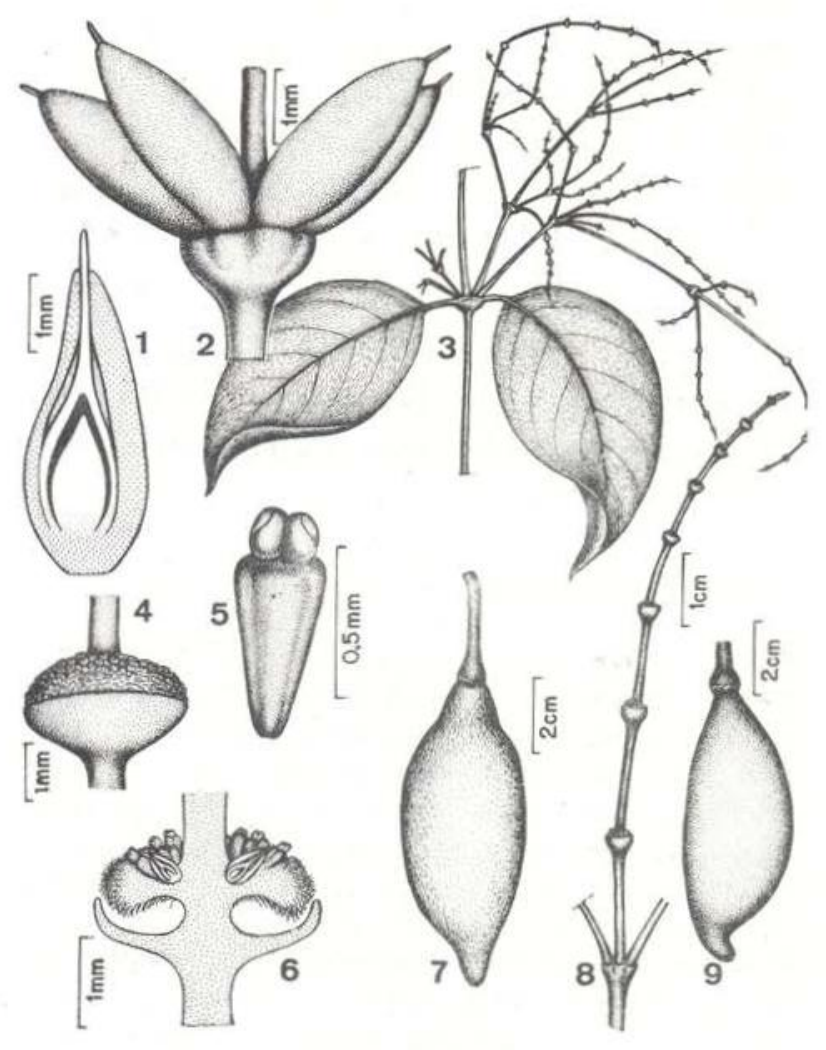

Est. 2 - Gnetum venosum: 1) corte longit. da $\mathrm{fl}$. fem.: 2) vertícilo de fl. fem.; 3) ramo com infl. masc.; 4)nódulo floral masc.; 5) microsporófilo; 6) corte de um nódulo floral masc. mostrando flores fem. estéreis: 7) fruto: 8) estróbilo ou espiga masc.: 9) fruto com ápice recurvado.

nós de comprimento variável; brácteas florais conchiformes, contendo cerca de 12 até 20 flores masculinas e poucas femininas, estéreis; flor masculina isolada obcônica, cerca de $0,75 \mathrm{~m} \mathrm{~m}$ de altura. Inflorescência feminina menos ramificada, flor feminina oblongo-acuminada, cerca de $3 \mathrm{~mm}$ de altura e $1 \mathrm{~mm}$ de espessura, invólucro externo espesso-carnoso, o médio cartáceo, o interno delgado, prolongado em tubo. Fruto elíptico-oblongo, de $6-8 \mathrm{~cm}$ de comprimento e $2,5-3 \mathrm{~cm}$ de diâmetro (os maiores do gênero), ligeiramente assimétrico, ápice acuminado às vezes recurvado; invólucro externo (casca) de cor amarelada, quando maduro, lenhoso fibroso; o médio crustáceo, às vezes mostrando lacunas em corte transversal; invólucro mais interno cartáceo, algo aderido à nucela.

G. venosum é muito freqüente nas várzeas do estuário e seu habitat preferido são as mar- 
gens alagadas dos rios, igarapés e furos. É a espécie que tem frutos maiores e uma de suas notáveis características são as folhas enegrecidas quando secas. Tais particularidades tornam a espécie inconfundivel, mesmo em estado estéril.

\section{LOCALIDADE TÍPICA}

Amazonas, igapó Manaquiri, confluência do rio Negro com o Solimões; junho, 1851. Tipo: R. Spruce 1579.

\section{COLEÇÕES EXAMINADAS}

PARA. Belém, beira do rio Guamá, lugar inundado, $\mathrm{fl}$. masc., 10-V-1949, N. T. Silva 300 (IAN); - ibidem, fl.. fem., 24-V-1949, Antonio Silva 445 (IAN); - ibidem, fr., mad., 19-XI 1949, G. A. Black 49-8572 (IAN); - ibidem, "ituá", fr. mad., 13-XII-1949, T. N. Guedes 228 (IAN); ibidem, fl. fem., 4-V-1950, T. N. Guedes 253 (IAN); ibidem, estéril, 12-IV-1950, G. A. Black 50-9368 (IAN); - ibidem, igarapé Murutucu, fr. imat., 19-XII-1950, J. M. Pires 2680 (IAN); - ibidem, fl. masc., 20-XII-1950. G. A. Black 50-10958 (IAN); - ibidem, fr. mad., 15-I-1951, J. M. Pires 3121 (IAN); - ibidem, "ituá", fr. imat., 20-VIII-1964, E. Oliveira 3129 (IAN). - Mosqueiro, Furo das Marinhas, junto à ponte, beira alagada, fr. imat., 10-IX-1977, P. Cavalcante \& Nelson Rosa, 3304 (MG). - Almeirim, rio Jari, entre Monte Dourado e Arapiranga, estéril, 22-VI-1968, E. Oliveira 4645 (IAN). - Monte Alegre, rio Maicuru, beira, fr. imat., 15-IX-1953. R. L. Fróes 30236 (IAN). - Oriximiná, rio Cuminá Mirim, lugar pedras, mata alagada, fl. masc., 24-V-1957, P. Cavaicante 102 e G. A. Black 57-19491 (MG, IAN); - ibidem, beira do rio, fr. imat., 9-VI-1957, P. Cavalcante 190 (MG).

AMAZONAS. Manaus, boca do rio Negro, fl. mas., V-1851, R. Spruce 1579 (isotipo MG). - Paraná do Careiro, boca do Solimões, lago Capitari, mata de várzea, fr. 12-11-1949, A. Ducke 2226 (IAN). - Paraná do Autaz-Mirim, solo sujeito à inundação temporária, fr., 22-VI-1966 W. Rodrigues \& F. Mello 7791 (INPA).

G. schwackeanum Taub. ex Schenck, in : Schimper Bot. Mittheil. 5, 2:249, 1823; Markgraf, I.c.: 450. (Est. 3)

Liana de porte pequeno ou médio, contendo um látex resinoso, pegajoso. Folha: pecío!o delicado, de $5: 10 \mathrm{~mm}$, lâmina elíptica ou elíptico-oblonga, subcoriácea até cartácea, levemente enegrecida na face superior e pardo-olivácea na inferior, "quando seca, até $12 \mathrm{~cm}$ por $6 \mathrm{~cm}$, sendo mais comum $6-7 \mathrm{~cm}$ por $3 \mathrm{~cm}$, base geralmente arredondada e ápice acuminado; nervu-

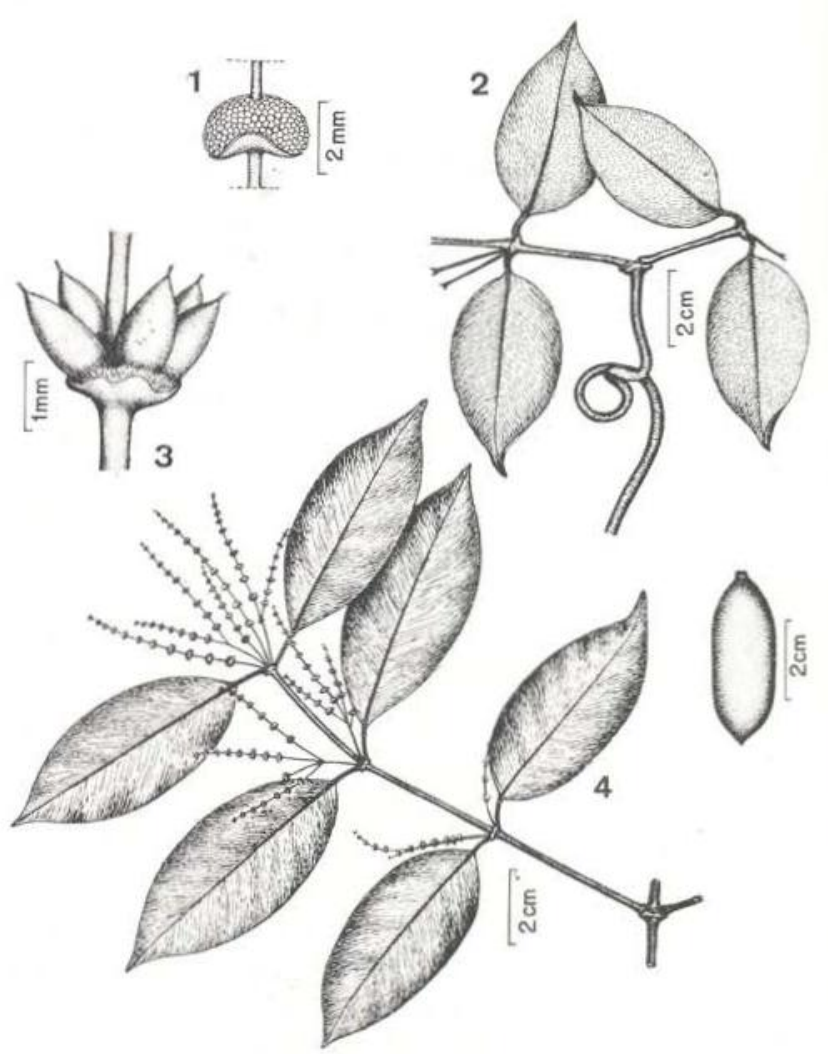

Est. 3 - Gnetum schwackeanum : 1) nódulo floral masc.; 2) folhas; 3) verticilo de fl. fem.; 4) ramo com infl. masc.; 5) fruto.

ras laterais bastante delicadas, cerca de 6 pares, na maioria das vezes indistintas a olho nu. Inflorescência masculina axilar e terminal, com ramificações delicadíssimas; verticilos de estróbilos distanciados de $8 \mathrm{~mm}$ na base da inflorescência, diminuindo gradativamente até $2 \mathrm{~mm}$ na extremidade; flores masculinas numerosas em 3-4 verticilos, sendo o mais superior constituido de flores femininas estéreis, entremeadas de tricomas brilhantes e moniliformes; brácteas dos nódulos florais quase planas ou em forma de prato, com a margem membranácea; perianto masculino cerca de $0,7 \mathrm{~mm}$ de altura, envolvendo um estame (raríssimo mais de um), com dois microsporângios levemente divergentes; flores femininas estéreis oblongoclavadas, cerca de $1 \mathrm{~mm}$ de altura; flor feminina fértil geralmente até 5 em cada bráctea colar, ovais, cerca de $2-2,5 \mathrm{~mm}$ de altura, invólucro externo carnoso, o médio cartáceo e o mais interno prolongado em tubo cerca de $0,5 \mathrm{~mm}$ 
exserto. Fruto vermelho até roxo-escuro, com látex branco, oblongo ou obovato-oblongo, $3,5-4,5 \mathrm{~cm}$ de comprimento por $1,8-2 \mathrm{~cm}$ de diâmetro; invólucro externo rígido-coriáceo, algo fibroso, cerca de $1 \mathrm{~mm}$ de espessura quando seco; invólucro médio crustáceo, pardo, longitudinalmente finíssimo-venoso; invólucro mais interno papiráceo, aderido à nucela, exceto nas extremidades.

O hábito de crescimento e o aspecto delicacio da inflorescência, bem como o tamanho e forma das folhas, tornam esta espécie muito semelhante a $G$. urens. A distinção de ambas baseia-se geralmente no comprimento dos entrenós da inflorescência, cor algo escura da folha, principalmente na face superior, e na forma das brácteas.

LOCALIDADE TÍPICA: Amazonas, Manaus, julho 1882. Tipo: Schwacke, III-788.

\section{COLEÇÕES EXAMINADAS}

PARÁ, Rio Tapajós, estrada das cachoeiras inferiores, perto de Furnas, mata de terra firme, fr. mad. purpúreo, 11-IX-1916, A. Ducke, MG 16474; - ibidem, Vila Nova, perto da cachoeira do Chacoräo, terra firme, fr. imat., 23-I-1952, J. M. Pires 4009 (IAN).

AMAZONAS. Manaus, estrada do Aleixo, sede do INPA, capoeira, fruto maduro vermelho, 6-XI-1974, G. T. Prance \& al. 20955 (INPA, MG). - Manaus, colônia Santo Antonio, Flores, capoeira baixa, fr. mad. roxo-escuro, 2-IV-1970, O. Pires Monteiro, INPA 28004; - ibidem, estrada antiga de São Raimundo, "itoá-i", fr., 24-X-1955. J. Chagas, INPA 2207. - Reserva Florestal Ducke, Q-17, mata de terra firme, fr., 30-X-1963, W. Rodrigues 5512 (INPA). - Estrada para a Reserva Florestal Ducke, fr. 7-III-1958, INPA 6152. - Rio Tarumá, mata de terra firme, fr. mad., 8-III-1946, A. Ducke 1927 (MG, IAN). Cachoeirinha, capoeira, fl. fem., 3-VIII-1900, E. Ule 5310 (MG). - Estrada Manaus-Itacoatiara, km 19, capoeira de terra firme, fr., 15-XI-1963, E. Oliveira 3055 (IAN). - Ibidem, km 64, Estação Biológica do INPA, mata de terra firme, fr., 30-XI-1962, W. Rodrigues 4838 (INPA). - Paraná do Autaz Mirim, mata de terra firme, fl. mas., 23-V!II-1973, G. T. Prance \& al. 19739 (MG, INPA). Rio Negro, Jupati, praia de areia e granito, fr., 17-IV-1947, J. M. Pires 336 (IAN). - Rio Negro, Tapuruquara, fr. mad. vermelho, 18-VI-1947, R. L. Fróes 22413 (IAN). - Rio Negro entre a ponta da ilha Maraiuá e Massarabi, caminho para Uaupés, fl. fem. e fr. jov., 1-V-1973, M. F. Silva \& al. 1218 (INPA). - Rio Negro, entre Remanso de Camanaus e Curicuriari, fr. mad. vermelho, 17-V-1973, M. F. Silva \& al. 1656 (INPA). - Rio Uaupés, fr. mad., 20-V-1975, L. Coelho 11 (INPA). - Rio Negro, Vila Içana, fr. mad. arroxeado, 20-IV-1947, J. M. Pires 434 (IAN). - Rio Jauaretê, $68^{\circ} \mathrm{W}^{\prime}-1^{\circ} 28^{\prime} \mathrm{N}$, fr.
18-V-1975, B. G. S. Ribeiro 971 (IAN). - Rio Purus, 'Lábrea, mata de várzea, fr. 30-X-1968, G. T. Prance \& al. 8091 (INPA). — Rio Madeira, Canumã, campinarana, fr. imat., 5-XI-1957, R. L. Fróes 33762 (IAN).

ACRE. Cruzeiro do Sul, estrada da Alemanha, mata 'de terra firme, fr., 15-IV-1971, G. T. Prance \& al. 11954 (INPA, MG).

G. paniculatum Spruce ex Benth., in : Hook., Journ. of Bot. and Kew Gard. Misc. 8:357. 1856: Markgraf, I.c. pag. 453. Sinônimo: $G$. microstachyum Spruce ex Benth., I.c. (Est. 4).

Cipó robusto, lenhoso, suberoso, trepador. Folha: peciolo de $0,5-1 \mathrm{~cm}$ de comprimento, lâmina coriácea às vezes parcialmente enegrecida quando seca, ovalada ou oblongo-elíptica, base arredondada ou subcordada, ápice acuminado ou curtamente assim, ligeiramente assimétrica, de $10-17 \mathrm{~cm}$ de comprimento e $5-9 \mathrm{~cm}$ de largura; nervura central supra impressa, as laterais bastante afastadas entre sí e as demais densamente reticuladas. Inflorescên-

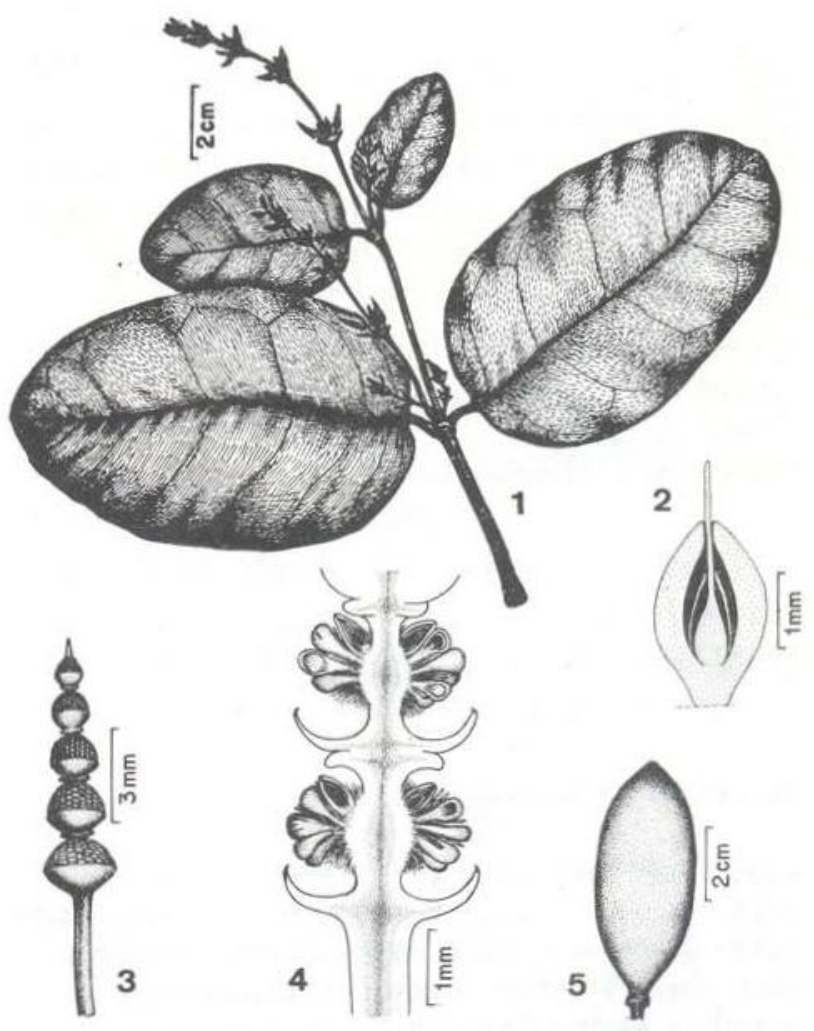

Est. 4 - Gnetum paniculatum : 1) ramo com infl. masc.; 2) corte long. de fl. fem.; 3) estróbilo masc.: 4) corte long. de dois nódulos florais mostrando $\mathrm{fl}$. fem. estéril; 5) fruto. 
cia masculina em panícula de $10-20 \mathrm{~cm}$, multiramificada, ramos suportando verticilo de estróbilos ou espigas curtamente pedicelados, com os nódulos florais bem aproximados; flores masculinas numerosas, cuneiformes, com um microsporófilo de $0,5 \mathrm{~mm}$ de altura e uma antera ou microsporângio globoso cơm duas lojas deiscentes por uma fenda transversal; flores femininas estéreis no mesmo nóduio formando um verticilo acima das masculinas, junto ao eixo do estróbilo. Inflorescência feminina em panícula menos ramificada do que a masculina; flor feminina fértil 2-3 em cada bráctea, elipsóide ou subglobosa, 2-2,5mm de altura; invólucro externo carnoso e o mais interno prolongado em tubo, cerca de $1 \mathrm{~mm}$ exserto. Fruto elíptico-oblongo-obtuso, até $6 \mathrm{~cm}$ de comprimento por $3 \mathrm{~cm}$ de diâmetro, cor da casca variando de vermelho até castanho quando maduro.

A primeira vista, algumas vezes esta espécie pode ser confundida com G. nodiflorum, mas somente na ausência de inflorescência de uma das duas espécies. No alto rio Negro, ambas as espécies são utilizadas na alimentação das populações ribeirinhas. Os índios comen os frutos assados ou então em forma de farinha ou de "beiju" (tapioca). Na língua Tucano estas espécies recebem o nome de "Coh-todá", que significa "cipó de corocoro" (pássaro). É conhecida, ainda, pelo nome de "curucuda", além de "ituá".

\section{LOCALIDADE TÍPICA}

Amazonas, Rio Negro, acima de Barcelos, dezembro de 1851; São Gabriel da Cachoeira, maio, 1852; Rio Uaupés, setembro, 1852. SINTIPOS R. Spruce 1923, 2314, 2554.

\section{COLEÇÕES EXAMINADAS}

AMAZONAS. Rio Solimões, São Paulo de Olivença, Camatiá, mata, fr. jov., 25-1-1949, R. L. Fróes 24004 (IAN). - Manaus, igarapé da cachoeira baixa do Tarumă, igapó, fl. 'masc., 22-VI-1955, Chagas, INPA 1237 - Estrada Manaus-Caracarai, km 45, campina, fr. mad., amarelado, 24-1I-1972, Honda \& Mello, INPA 35214; ibidem, mata de terra firme, fr. jov., 12-l-1972, Loureiro \& Monteiro 40 (INPA). - Rio Cuieiras, abaixo da boca do rio Branquinho, margem alagada, fr. jov., 26-IX-1971, G. T. Prance \& al. 14926 (INPA, MG). - Rio Negro, rio Preto, afluente do Padauiri, fl. masc., 8-IX-1947.
R. L. Fróes 22782 (IAN). - Rio Negro, Ilha Grande, rio Uneiuxi, floresta de savana inundada, fr., 22-X-1971. G. T. Prance \& al. 15550 (INPA, MG) - Barcelos, beira de um paraná, fl, jov., 27-VI-1905, A. Ducke, MG 7177. - Rio Negro, entre a boca Arirahara e paraná de S. José, caminho de Tapuruquara; fr. marron-amarelado, 30-IV-1975, M. F. Silva \& al. 1162 (INPA, MG). - São Gabriel da Cachoeira, Serra Uanari, catinga, fr., 30-X-1947, J. M. Pires 788 (IAN); - ibidem, beira dágua, fr. jov., 31-X-1947, J. M. Pires 807 (IAN): ibidem, beira do rio, "corocuda", fr. imat., 17-X-1947. J. M. Pires 1166 (IAN). - Alto rio Negro, Cucuí, junto ao marco de fronteira, fr. imat., 4-V-1975, P. Cavalcante 3102 (MG); - ibidem, fr. imat., 25-IV-1975, 0. C. Nascimento \& al. 196 (MG, IAN); - ibidem, fr. imat., 5-V 1973, M. F. Silva \& al. 1264 (INPA). - Rio Negro, Içana, Acotiacanga, fr., 27-IV 1947, R. L. Fróes 22239 (IAN); - ibidem, fl. jov., 25-III-1951, R. L. Fróes 28025 (IAN). - Rio Negro, Pari-Cachoeiras, rio Tiquiê, campina, estéril, 13-XII-1975, L. Coelho \& Francisco 246 (INPA). - Rio Içana, estirão Santana, fr. mad., 22-1II-1952, R. L. Fróes 27982 (IAN). - Rio Uaupés, Taraquá, fr. mad. vermelho, 3-III-1959, P. Cavalcante 742 (MG); - ibidem, catinga, fr. mat. arroxeado, 10-XI-1947. J. M. Pires 1000 (IAN). - Rio Negro, São Felipe, igarapé Turi, fl. masc., 27-IX-1952, R. L. Fróes 28780 (IAN): - ibidem, "curucuda", fr. mad., 4/7-IV-1948, R. E. Schultes \& F. Lopez 9772 (IAN); - ibidem, fr. jov., 27-IX-1952, R. L. Fróes 28783 (IAN). - Alto Rio Negro, rio Xiê, fr. mad, castanho, 8-V-1973, M. F. Silva \& al. 1333 (INPA). - Rio Acará, fl. masc.. 29-X-1952, Fróes \& Addison 29150 (IAN). - Rio Dimiti, fl. masc., 12/19-V-1948, R. E. Schultes \& F. Lopez 9914 (IAN).

T. F. RORAIMA. Rio Univini, igarapé do campo, fr. 24-IV-1974, Pires \& al. 14248 (IAN). - Caracarai, rodovia Perimetral Norte, mata de catinga, fr., 27-IV-1974, Pires \& al. 14365 (IAN).

G. urens (Aubl.) BI., Tijdschr. Natuurl. Geschied 1:155, 1834, Markgraf, I.c., pag. 454. Sin.: Thoa urens Aubl., Pl. Guyan. Franç. 2:874, t. 336, 1775; G. meliononii Benoist, Bull. Mus. Hist. Nat., Paris 2 ser. 17:66, 1945 (Est. 5) .

Escandente, de porte delicado. Folha: pecíolo de $5-8 \mathrm{~mm}$ de comprimento e $1 \mathrm{~mm}$ de espessura, com alas superiores formando canaleta; lâmina, quando seca, verde-amareladobrilhosa, subcoriácea, elíptica, no máximo até $12 \mathrm{~cm}$ de comprimento e $5 \mathrm{~cm}$ de largura, base aguda até subarredondada, ápice curtamente acuminado; faces, superior e inferior, copiosa. mente estriadas pela presença de fibras paralelas em direção à margem; nervuras laterais apenas perceptíveis, anastomosadas cerca de 5-8 $\mathrm{mm}$ das margens. Inflorescência masculina reduzida, pouco ramificada; flor masculina mui- 


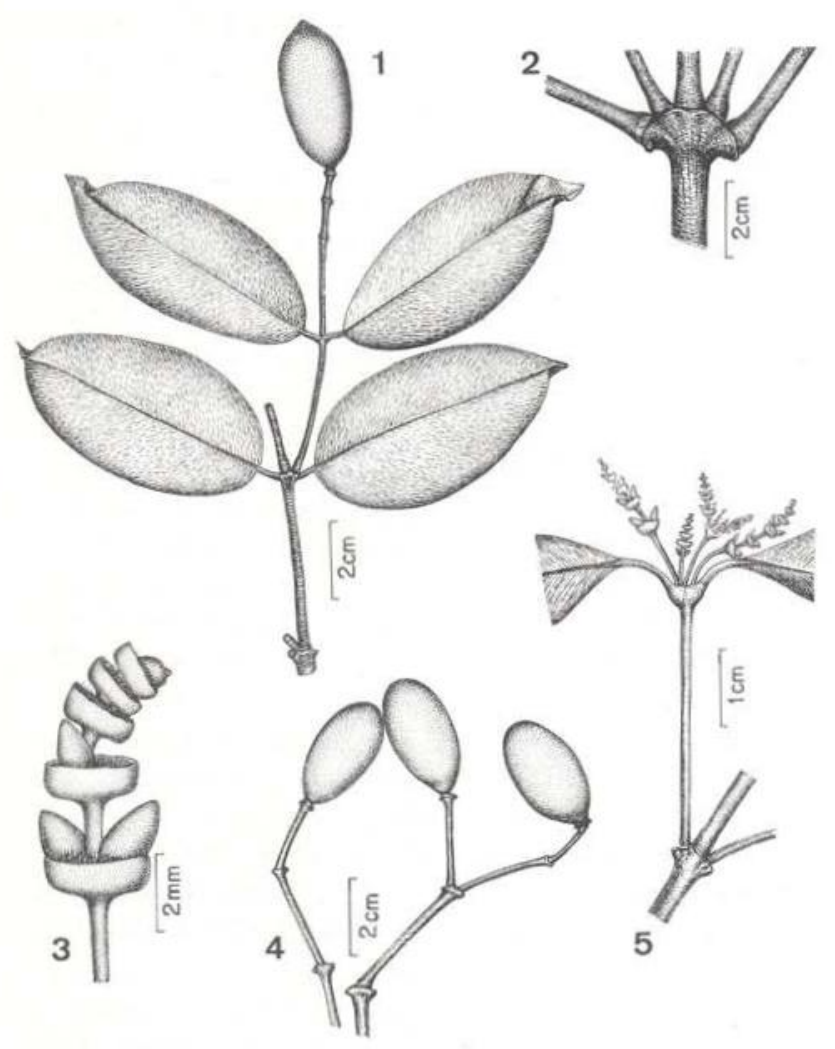

Est. 5-Gnetum urens : 1) ramo com fruto; 2) detalhe de ramificação: 3) estróbilo fem.: 4) fruto; 5) infl. fem.

to mais numerosa do que as flores femininas estéreis; flores femininas férteis oblongas, cerca de $3 \mathrm{~mm}$ de altura, invólucro externo car. noso-fibroso, até $1 \mathrm{~mm}$ de espessura, invólucro médio cartáceo e invólucro mais interno prolongado em tubo, cerca de $0,5 \mathrm{~mm}$ exserto. Frutos elipsóides ou levemente obovados, até $4 \mathrm{~cm}$ । de comprimento por $1,5 \mathrm{~cm}$ de diâmetro, casca vermelha quando maduro, pardo-amarelado e minuto-estriado quando seco, extremidade com um apículo pequeníssimo.

Espécie muito aproximada de G. schwackeanum com a qual pode muitas vezes ser confundida, na ausência de inflorescência, posto que até os frutos são semelhantes. A cor escura da face superior das folhas de $G$. schwackeanum já permite uma separação. LOCALIDADE TÍPICA: Guiana Francesa.

\section{COLEÇÕES EXAMINADAS}

PARA. Belém, Instituto Agronômico do Norte (atualmente EMBRAPA-Pará), mata do Mocambo, fr. mad.,
XI-1951, G. A. Black 51-14108 (IAN); - ibidem, capoeira 157-L, fr. mad. vermelho, .2-III-1955, G. A. Black 55-18133 (IAN). - Peixe-Boi, campo, fl. masc., 30-VIII-1949, N. T. Silva 328 (IAN), - Santa Izabel do Pará, fr. mad., 13-V-1956, Feliciano Ferreira, IAN 90495. - Estrada de Tracuateua, capoeira, fr. mad. vermelho, 11-VIII-1952, R. L. Fróes 28489 (IAN). - Almeirim, rio Jari, Monte Dourado, atrás dos alojamentos do S-40, capoeira de terra firme, fr., 23-IV-1968, E. Oliveira 4308 (IAN): - ibidem, mata alta de terra firme, fr. mad., 2-II-1968, E. Oliveira 4083 (IAN).

T. F. AMAPA. Calçoene, estrada para as minas de ouro, mata de solo pedregoso, fr. imat., 20 VIII-1962, Pires \& Cavalcante (MG, IAN, NY, Amapá-Guyana 52521).

G. leyboldii Tul., Ann. Sc. Nat. ser 4, $10: 115$, 1858; Markgraf, I.C., pag. 452 (Est. 6) .

Cipó lenhoso geralmente robusto, apoiado em árvores altas até cerca de $30 \mathrm{~m}$, ramos com articulações dilatadas. Folha: pecíolo até $1,5 \mathrm{~cm}$ de comprimento, lâmina coriácea variando de $15-20 \mathrm{~cm}$ de comprimento por $6-12 \mathrm{~cm}$ de largura, base arredondada ou subcordada e

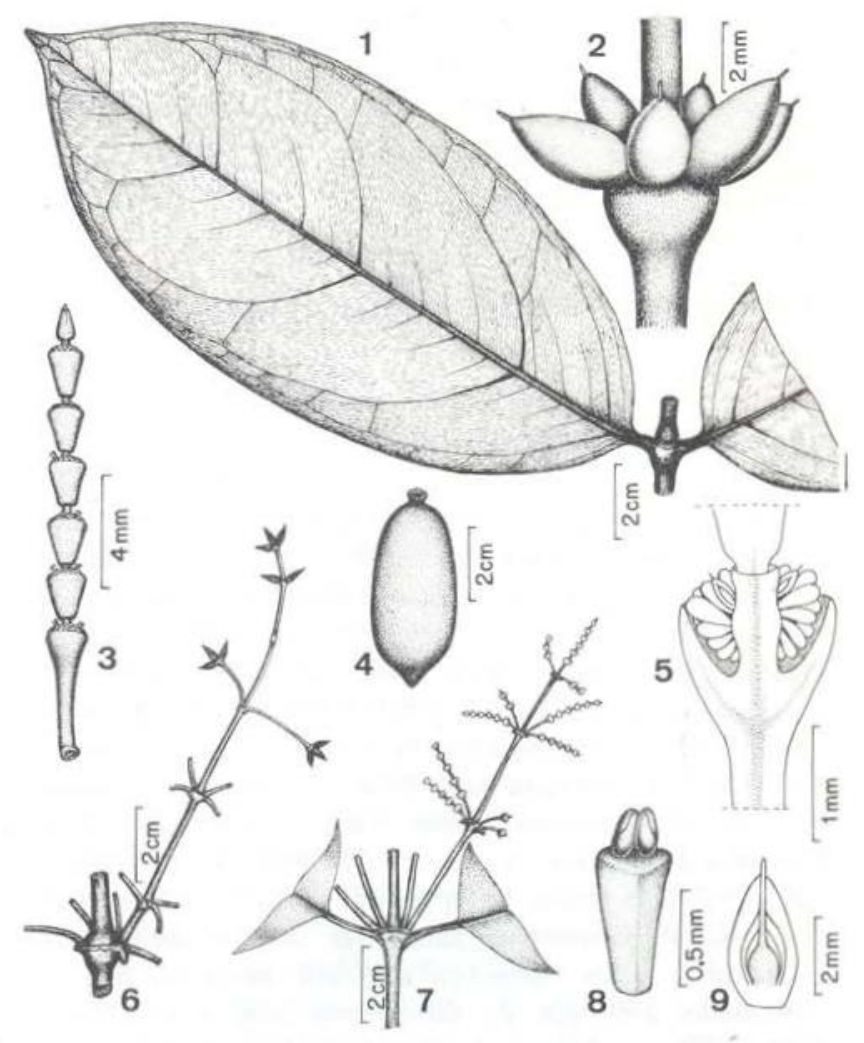

Est. 6-Gnetum leyboldii : 1) folha; 2) verticilo de fl. fem.; 3) estróbilo masc.; 4) fruto; 5) corte long. de um nódulo masc.; 6) infl. fem.; 7) infl. masc.; 8) microsporófilo; 9) corte long. de fl. fem. 
ápice agudo ou curto-acuminado; nervura central levemente depressa na face superior e proeminente na inferior; nervuras laterais cerca de 4 pares, bastante distanciadas, fortemente arqueadas em direção ao ápice, obscuras na face superior. Inflorescência masculina em panícula laxa geralmente com ramos patentes, estróbilos com o pedicelo cerca de $3 \mathrm{~cm}$ de comprimento, nódulos florais distanciados de apenas $1 \mathrm{~mm}$, ou menos, brácteas colares obcônicas, com numerosas flores masculinas e poucas femininas estéreis. Inflorescência feminina menos ramificada, com os nódulos florais separados em espaços de $0,5-1 \mathrm{~cm}$; flores femininas até $6 \mathrm{em}$ cada bráctea colar, elipsóides, cerca de $4-5 \mathrm{~mm}$ de altura com o invólucro mais interno prolongado em tubo, $1 \mathrm{~mm}$ exserto. Fruto maduro vermelho, oblongo, $4,5-5 \mathrm{~cm}$ de comprimento e $2 \mathrm{~cm}$ de diâmetro.

Em G. nodiflorum, já se fez referência à semelhança entre as duas espécies. Como observa Markgraf (l.c.), é impossivel a distinção de exemplares estéreis das duas espécies em apreço, pois a forma, consistência e tamanho das folhas são as mesmas em ambas. A distinção principal reside nas inflorescências, isto é, no afastamento dos nódulos florais, a forma das brácteas colares e, por último, os frutos.

LOCALIDADE TÍPICA: Amazonas, Tefé, Martius, nov. 1819.

\section{COLEÇÕES EXAMINADAS}

PARA. Belém, beira do rio Guamá, igapó, fl. jov., 26-IV-1949, N. T. Silva 270 (IAN); - ibidem, fr. verde-claro, 19-XI-1949, G. A. Black 49-8571 (IAN); - ibidem, reserva APEG, Q-183-8, fl. masc., 20-VII-1967, J. M. Pires \& N. T. Silva 10600 (IAN). - Ananindeua, margem esquerda do Aurá, estéril, 5-IV_1977, N. A. Rosa 1835 (MG). - Ilha do Outeiro, beira da praia, fl. fem., 31-VII-1970, E. Oliveira 5242 (IAN). - Ilha do Mosqueiro, furo das Marinhas, ponte, lado do continente, local inundado pela maré, fr. jov., 10-IX-1977, P. Cavalcante 3305 (MG) . - Acará, beira do rio, mata, fl. masc. jov., 1-VI-1969, P. Cavalcante 2204 e D. Austin 4074 (MG); - Ibidem, entre Tomé-Açu e Acará, beira do rio, fr. amarelado, 3-VI-1969, P. Cavaicante 2236 e D. Austin 4109 (MG). - Breves, beira do rio Mapuá, fl. masc., 18-VIII-1950, G. A. Black \& P. Ledoux 50-9081 (IAN). ibidem, Antonic Lemos, várzea do igarapé Pixuna, fl. masc., 19-VII-1948, G. A. Black 48-2967 (IAN); - ibidem, Furos, fl. masc., 16-VII-1950, G. A. Black \& P. Ledoux 50-9783 (IAN); - ibidem, Vila Nova do Aramá, mata da beira do rio, fl. fem., 23-IX-1968, P. Cavalcante 2030 (MG). - Portel, região do Anapu, rio Flexal, fr. jov., 30-IX-1956, R. L. Fróes 32758 (IAN); - ibidem, rio Maparauá, fr. jov., 5-VIII-1956, R. L. Fróes 32935 (IAN): - ibidem, rio Pracajai, fr. jov., 14-IX-1956, R. L. Fróes 32746 (IAN). - Rio Jari, Monte Dourado, mata de várzea, fr. jov., 9-VII-1966, N. T. Silva 2374 (IAN); — ibidem, fl. masc., 28-IV_1969, N. T. Silva 1937 (IAN); - ibidem, estrada de S. Miguel, fr. jov., 8-IX-1969, N. T. Silva 2774 (IAN). - Porto de Moz, rio Jaraucu, beira, fr. imat., 11-IX-1955, R. L. Fróes 32191 (IAN). Santarém, rio Curuauna, várzea, fl. fem., X-1954, R. L. Fróes 31343 (IAN); - ibidem, fr. imat., 23-X-1954, R. L. Fróes 31217 (IAN). - Alto Tapajós, Missão Cururu, várzea, fl, masc., 22-XI-1959, W. A. Egler 934 (MG, (AN). - Oriximiná, rio Trombetas, cachoeira Porteira, fl. jov., 2-VI-1974, G. T. Prance \& al. 22455 (INPA, MG); — ibidem, várzea, "ituã", fr imat, 21-1-1968, M. G. Silva 1271 (MG).

T. F. AMAPÁ. Rio Araguari, abaixo de Porto Platon, fr. jov., 21-IX-1961, Pires, Rodrigues \& Irvine (MG, IAN, NY, Amapá-Guayana 51148); - ibidem, fl. masc. 15-VIII-1961, Pires, Rodrigues \& Irvine (MG, IAN, NY, Amapá-Guayana 50347). - Rio Flexal, frequente na beira, fl. masc., 11-VIII-1962, Pires \& Cavalcante (MG, IAN, NY, Amapá-Guayana 52487).

AMAZONAS. Manaus, estrada Caracaraí, reserva da campina, fr. imat., 24-XI-1973, G. T. Prance 17683 (INPA). - Maués, praia alagável de rio, cipó muito grande, fl. masc., 30-XI-1946, J. M. Pires 54 (IAN). Rio Negro, Içana, mata, "corocoro", fr. mad. marron, 28-IV-1947, R. L. Fróes 22258 (IAN). - Tefé, rio Pixiubinha, mata, fl. masc., 17-VI-1950, R. L. Fróes 26292 (IAN). - Rio Madeira, Humaitá, rio Ipixuna entre Monte Cristo e Santa Vitória, fr. mad., 15/17-XI-1934, B. A. Krukoff's 5 exp., 7264 (IAN); - ibidem, 'ituá", fr. mad., 26-XI-1966, G. T. Prance \& al. 3365 (INPA, MG).

T. F. RONDONIA. Rio Guaporé, Ponta das Pedras Negras, capoeira, fl. masc., 18.VI-1952, G. A. Black \& E. Cordeiro 52-15088 (IAN).

MATO GROSSO. Rio Aripuanä, acima da cachoeira Andorinha, várzea, fr. mad. 20-X-1973, G. T. Prance \& al. 18698 (INPA, MG).

\section{OBSERVAÇÕES FINAIS}

A literatura básica, que trata da taxonomia das gnetáceas amazônicas, praticamente restringe-se a dois trabalhos: a) Monografia realizada por L. R. Tulasne para a Flora Brasiliensis, em 1863 (há mais de 100 anos); b) o trabalho de Markgraf (em alemão) feito em 1930 (quase 50 anos); c) vale citar aqui a recente publicação (1961) de Maheshwari \& Vasil, que resume quase todos os trabalhos sobre morfologia, anatomia e embriologia do gênero, porém referido às espécies asiáticas $\mathrm{e}$ africanas. 
É até singular o fato de que, decorrido mais de um século, desde a publicação de Tulasne, somente duas espécies foram acrescidas ao gênero, atualmente com seis espécies válidas na Amazônia. Apenas, vale ressaltar, foi criada uma variedade para $G$. leyboldii por Markgraf (1965: 385), coletada entre a Colômbia e o Panamá. O número de espécies já andou por volta de 13-14. porém 7-8 foram reduzidas a sinônimos, por razões óbvias. G. microstachyum, por exemplo, foi descrito por Bentham. como espécie nova, afim de G. paniculatum. quando, na realidade, tratava-se da planta feminina da última. O próprio autor, logo em seguida reconheceu o engano. Situações análogas tem ocorrido com outros.

Conclui-se que um estudo baseado em material farto e completo (exemplares da mesma espécie com flores dos dois sexos e frutos). por certo reduziria o número de espécies e. neste caso, situamos G. urens com G. schwackeanum, espécies bastante afins, cuja distinção na maioria dos casos permanece duvidosa.

É de se supor que as gnetáceas poderiam ser um grupo muito antigo e as espécies atuais seriam relíctos porque, aparentemente, não prodiuzem formas novas.

\section{COLEÇÕES CITADAS}

ALBUQUerque, Byron Wilson Pereira de 591 - G. nodiflorum

BLACK, George Alexandre

\begin{tabular}{|c|c|c|}
\hline & - & G. I \\
\hline & - & G. \\
\hline & - & G. \\
\hline & - & G. If \\
\hline & - & G. \\
\hline & - & G. I \\
\hline & - & G. \\
\hline & - & \\
\hline & - & G. \\
\hline 801 & - & G. \\
\hline 72 & - & G. \\
\hline 924 & - & G. $r$ \\
\hline 958 & - & G. \\
\hline & - & G. \\
\hline 088 & - & G. \\
\hline 16284 & - & G. \\
\hline-1693 & - & G. $r$ \\
\hline 60 & - & G. \\
\hline & - & G. \\
\hline & - & \\
\hline 9125 & - & G. noumot \\
\hline
\end{tabular}

CAVALCANTE, Paulo B.

$$
\begin{aligned}
& 102-\text { G. venosum } \\
& 190 \text { - G. venosum } \\
& 742-\text { G. paniculatum } \\
& 2030 \text { - G. leyboldii } \\
& 2204-\text { G. leyboldii } \\
& 2236 \text { - G. leyboldii } \\
& 3102 \text { - G. paniculatum } \\
& 3304 \text { - G. venosum } \\
& 3305 \text { - G. leyboldii }
\end{aligned}
$$

COELHO, Luiz \& al.

$$
\begin{aligned}
& 11-\text { G. schwackeanum } \\
& 246-\text { G. paniculatum } \\
& 338-\text { G. nodiflorum }
\end{aligned}
$$

DUCKE, Adolfo

$$
\begin{aligned}
& 1927 \text { - G. schwackeanum } \\
& 2067 \text { - G. nodiflorum } \\
& 2226 \text { - G. venosum } \\
& \text { MG } 7177 \text { - G. paniculatum } \\
& \text { MG } 8581 \text { - G. nodiflorum } \\
& \text { MG } 9044 \text { - G. nodiflorum } \\
& \text { MG10824 - G. nodiflorum } \\
& \text { MG16474 - G. schwackeanum }
\end{aligned}
$$

EGLER, Walter A

$$
\begin{aligned}
& 330-\text { G. nodiflorum } \\
& 379-\text { G. nodiflorum } \\
& 934-\text { G. leyboldii }
\end{aligned}
$$

FERREIRA, Feličiano IAN90495 - G. urens

FRÓES, Ricardo Lemos

$$
\begin{aligned}
& 22235 \text { - G. leyboldii } \\
& 22239 \text { - G. paniculatum } \\
& 22258 \text { - G. leyboldii } \\
& 22413 \text { - G. schwackeanum } \\
& 22782 \text { - G. paniculatum } \\
& 24004 \text { - G. paniculattum } \\
& 24030 \text { - G. nodiflorum } \\
& 24220 \text { - G. nodiflorum } \\
& 24973 \text { - G. nodiflorum } \\
& 25341 \text { - G. nodiflorum } \\
& 25464 \text { - G. nodiflorum } \\
& 26282 \text { - G. nodiflorum } \\
& 26292 \text { - G. leyboldii } \\
& 26353 \text { - G. nodiflorum } \\
& 26360 \text { - G. nodiflorum } \\
& 26978 \text { - G. nodiflorum } \\
& 27569 \text { - G. nodiflorum } \\
& 27982 \text { - G. paniculatum } \\
& 28025 \text { - G. paniculatum } \\
& 28489 \text { - G. urens } \\
& 28780 \text { - G. paniculatum } \\
& 28783 \text { - G. paniculatum } \\
& 29047 \text { - G. nodiflorum } \\
& 29150 \text { - G. paniculatum } \\
& 29179 \text { - G. nodiflorum } \\
& 30236 \text { - G. venosum } \\
& 31217 \text { - G. leyboldii } \\
& 31343 \text { - G. leyboldii } \\
& 31608 \text { - G. nodifiorum } \\
& 31640 \text { - G. nodiflorum }
\end{aligned}
$$




$$
\begin{aligned}
& 31643-\text { G. nodiflorum } \\
& 32028-\text { G. nodiflorum } \\
& 32191-\text { G. leyboldii } \\
& 32746-\text { G. leyboldii } \\
& 32758-\text { G. leyboldii } \\
& 32935-\text { G. leyboldii } \\
& 33131-\text { G. nodiflorum } \\
& 33762-\text { G. schwackeanum }
\end{aligned}
$$

GUEDES, M.

MG2214 - G. nodiflorum

GUEDES, Temistocles N.

$$
\begin{aligned}
& 228 \text { a }- \text { G. nodiflorum } \\
& 228 \text { - G. venosum } \\
& 253 \text { - G. venosum } \\
& 661 \text { - G. nodiflorum }
\end{aligned}
$$$$
\text { IAN71152 - G. venosum }
$$$$
\text { HUBER, Jacques }
$$

MG1031 - G. nodiflorum MG1863 - G. nodiflorum IFAT

$$
\text { INPA }
$$$$
7921 \text { - G. nodiflorum }
$$

$$
\begin{array}{r}
1237 \text { - G. paniculatum } \\
2207 \text { - G. schwackeanum } \\
6152 \text { - G. schwackeanum } \\
28004 \text { - G. schwackeanum } \\
35214 \text { - G. paniculatum } \\
55813 \text { - G. paniculatum }
\end{array}
$$

KRUKOFF, B. A.

7264 - G. leyboldii

LISBOA, P.

$$
472 \text { - G. nodiflorum }
$$

LOUREIRO, A. \& al.

40 - G. paniculatum

NASCIMENTO, Osvaldo Cardoso do 196 - G. paniculatum

NY-AMAPA-GUAYANA 50347 - G. leyboldii 50383 - G. nodiflorum 51148 - G. leyboidii 52260 - G. nodiflorum 52487 - G. leyboldii 52521 - G. urens

OLIVEIRA, Emanuel 1682 - G. nodiflorum 1679 - G. nodiflorum 2559 - G. nodiflorum 3129 - G. venosum 3055 - G. schwackeanum 4083 - G. urens 4205 - G. nodiflorum

4308 - G. urens 4645 - G. venosum 5242 - G. leyboldii 5422 - G. nodiflorum

PENA, Bento da Silva $339 \rightarrow$ G. nodiflorum

PIRES, João Murça

$$
\begin{aligned}
54 & - \text { G. leyboldii } \\
336 & - \text { G. schwackeanum }
\end{aligned}
$$

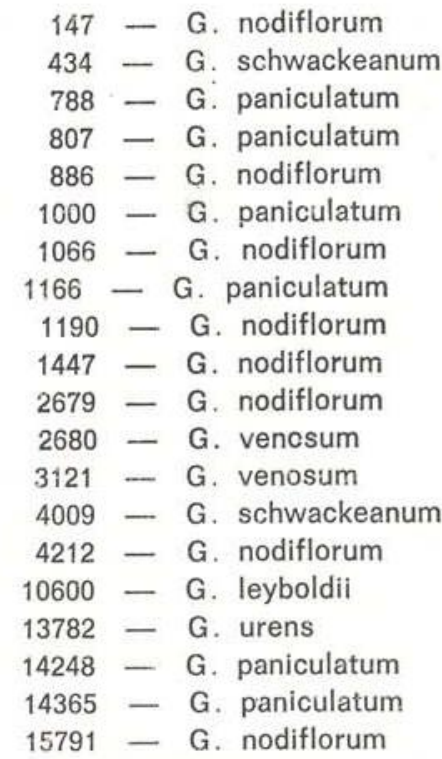

P. L. K. \& ELIANA (INPA)

12762 - G. paniculatum

PRANCE, Ghillean T.

$$
\begin{aligned}
& 1436 \text { - G. nodiflorum } \\
& 3365 \text { - G. leyboldii } \\
& 4939 \text { - G. nodiflorum } \\
& 8901-\text { G. schwackeanum } \\
& 11954 \text { - G. schwackeanum } \\
& 12096 \text { - G. nodiflorum } \\
& 14485 \text { - G. nodiflorum } \\
& 14507 \text { - G. nodiflorum } \\
& 14817 \text { - G. nodiflorum } \\
& 14926 \text { - G. paniculatum } \\
& 15550 \text { - G. paniculatum } \\
& 17000 \text { - G. nodiflorum } \\
& 17072 \text { - G. nodiflorum } \\
& 17683 \text { - G. leyboldii } \\
& 17817 \text { - G. paniculatum } \\
& 18698 \text { - G. leyboldii } \\
& 19739 \text { - G. schwackeanum } \\
& 20955 \text { - G. schwackeanum } \\
& 20985 \text { - G. nodiflorum } \\
& 22455 \text { - G. leyboldii } \\
& 23394 \text { - G. nodiflorum }
\end{aligned}
$$

RIBEIRO, Benedito G. Santos

$$
971 \text { - G. schwckeanum }
$$$$
1379 \text { - G. nodiflorum }
$$

RODRIGUES, William A.

$$
\begin{aligned}
& 4838 \text { - G. schwackeanum } \\
& 5512 \text { - G. schwackeanum } \\
& 7791 \text { - G. venosum }
\end{aligned}
$$

ROSA, Nelson A.

$$
1835 \text { - G. leyboldii }
$$

SILVA, Antonio

445 - G. venosum

SILVA, Marlene F. da

$$
\begin{aligned}
52 & - \text { G. nodiflorum } \\
831 & - \text { G. nodiflorum } \\
1162 & - \text { G. paniculatum } \\
1218 & - \text { G. schwackeanum }
\end{aligned}
$$




$$
\begin{aligned}
& 1264 \text { - G. paniculatum } \\
& 1333 \text { - G. paniculatum } \\
& 1656 \text { - G. schwackeanum }
\end{aligned}
$$

SILVA, Milton G.

$$
1271 \text { - G. leyboldii }
$$

SILVA, Nilo T.

$$
\begin{aligned}
& 109-\text { G. nodiflorum } \\
& 270-\text { G. leyboldii } \\
& 300-\text { G. venosum } \\
& 328-\text { G. urens } \\
& 1319-\text { G. nodiflorum } \\
& 1842-\text { G. leyboldii } \\
& 1937-\text { G. leyboldii } \\
& 2374-\text { G. leyboldii } \\
& 2774-\text { G. leyboldii }
\end{aligned}
$$

SCHULTES, Richard E. \& al.

$$
5436 \text { - G. nodiflorum }
$$

8151 - G. schwackeanum

9166 - G. paniculatum

9462 - G. nodiflorum

9706 - G. paniculatum

9772 - G. paniculatum

9914 - G. paniculatum

9994 - G. paniculatum

10146 - G. paniculatum

26163A - G. nodiflorum

SPRUCE, Richard

$$
\begin{aligned}
& 1579 \text { - G. venosum } \\
& 1923 \text { - G. venosum }
\end{aligned}
$$

ULE, E.

$$
5310 \text { - G. schwackeanum }
$$

\section{SUMMARY}

In the present contribution, the author updates the geographic distribution of the six species of the genus Gnetum in the Amazonian region, based on field observations and material of the herbaria INPA, MG and IAN. Some unusual distribution patterns are pointed out for each species. G. paniculatum and G. schwackeanum are restricted to the State of Amazonas and G. urens to Pará. G. nodiflorum is dispersed to the north of the region and less common $\mathbf{G}$. leyboldii is found more to the south. G. venosum is distributed from the estuary, in Pará, up to Manaus. The different kinds of habitats of the species are also discussed, as well as, their economic importance. The taxonomy is treated in species descriptions and a key to identify them. It is suggested that a careful study, based on good and abundant material, would probably reduce the number of species because of the apparent small amount of interspecific variation between some species, presently recognized.

\section{BIBLIOGRAFIA CITADA}

BENTHAM, G.

1856 - Description of two American Species of Gnetum. In: Hook. Journ. of Bot. and Kew Gard. Misc., 8 : 357.

Croizat, LÉON

1952 - Manual of Phytogeography; or an account of plant_dispersal throughout the world. Hague, W. Junk, p. 277-9.

EAMES, A. J.

1952 - Relationships of the Ephedrales. Phytomorphology, 2: 79

LAWRENCE, George H. M.

1958 - Taxonomy of vascular plant. 3. ed. N. York, MacMillan, p. 368.

MARKGRAF, Fr.

1930 - Monographie der Gattung Gnetum. Bull. Jard. Bot. Buitenz. Ser. 3, 9(4) : 448-455.

1965 - New discoveries of Gnetum in Trop. America. Ann. Mis. Bot., 52: 385.

Maheshwari, P. \& Vasil, Vimla

1961 - Gnetum. New Delhi, Council of Scientific \& Industrial Research, c. 1961, 142 p. (Botanical Monography, 1).

Medina, Julio̊ Cesar

1959 - Plantas fibrosas da Flora Mundial Campinas, Instituto Agronômico, p. 45.

TUlasne, L. R.

1863 - Gnetaceae. In Martius, C. F. P. von - Flora Brasiliensis. Monachii, Fried. Freischer, 15 v.. 4 pt. 1), p. 398.

(Aceito para publicação em 10/01/78) 